\title{
Perspectivas sobre mediação, apropriação e visibilidade do lazer no Instagram
}

\author{
Perspectives on mediation, appropriation and leisure visibility in the Instagram \\ Perspectivas sobre mediación, apropriación y visibilidade del ócio em Instagram
}

Vivianne Limeira Azevedo Gomes - Universidade Federal do Rio Grande do Norte | Natal | RN | Brasil | vivianne.limeira@gmail.com | https://orcid.org/0000-00030082-0482

Resumo: Este artigo apresenta a discussão sobre mediação do lazer, aliado a conjuntura da visibilidade às visualidades desta prática pela apropriação da hashtag \#lazer no Instagram, trabalhada na pesquisa Mediações do Lazer no Instagram. Concebida através de apreensões teóricas já realizadas, constituindo-se de um recorte exploratório e de caráter descritivo. Os resultados confirmam os processos técnico-culturais da comunicação trazidos por e da interação em perspectiva ao lazer midiatizado na rede, seja a partir das diversas expressões de grupos sociais e indivíduos que consomem e (re)produzem conteúdos, por meio de imagens, seja pelas visualidades na interação mediada pela hashtag \#lazer, em que constituem e possibilitam mecanismos de entendimento para ressignificação e ampliação do que se compreende por lazer.

Palavras-chave: Mediação. Visualidades. Lazer.

Abstract: This paper presents the discussion of leisure mediation, allied to the conjuncture of visibility to the visualities of this practice by the appropriation of hashtag \#lazer in Instagram, worked on the research Mediation of Leisure in Instagram. Conceived through theoretical apprehensions already carried out, constituting an exploratory and descriptive cut. The results confirm the technical-cultural processes of communication and the interaction in perspective to the mediated leisure in the network, either from the various expressions of social groups and individuals who consume and (re)produce content, through images, or by the visualities in the interaction mediated by hashtag \#lazer, showing points of resignification and expansion of what is understood as leisure.

Key words: Mediation. Visualities. Leisure.

Resumen: Este artículo presenta la discussion sobre la mediación del ocio, aliados a la coyuntura de visibilidad a las visualidades de esta práctica por la apropiación de hashtag \#lazer en Instagram, trabajada en la investigación Mediación del Ocio en Instagram. Concebido a través de aprehensiones teóricas ya realizadas, constituyendo un corte exploratorio y descriptivo. Los resultados confirman los procesos técnico-culturales de comunicación aportados por y la interacción en perspectiva al ocio mediado en la red, ya sea desde las diversas expresiones de grupos sociales e individuos que consumen y (re)producencontenidos, a través de imágenes, o por las visualidades en la interacción mediada por hashtag \#lazer, mostrando puntos de resignificación y expansión de lo que se entiende por ocio.

Palabras clave: Mediación. Visualidades. Ocio. 


\section{Introdução}

O presente artigo traz a discussão sobre mediação, apropriação e visibilidade para pensar as práticas sociais de lazer no Instagram, desenvolvida por Limeira (2018), em pesquisa intitulada Mediações do Lazer no Instagram: imagens, visualidades e sentidos. $O$ objetivo do estudo foi problematizar a compreensão de lazer a partir das visualidades desta prática pelo uso da hashtag\#lazer e do conjunto de tags associadas que alimentam os mecanismos de interação entre os perfis e suas redes. A partir da hipótese de que a exposição de imagens compartilhadas na plataforma Instagram com a hashtag\#lazer e mediadas pelos conjuntos de tags nas imagens permite a apropriação de novos sentidos e significados ao lazer contemporâneo e consumo visual desses conteúdos na rede, foi possível identificar o conteúdo de lazer expresso pelos usuários e as possíveis correlações de sentido nas imagens.

O critério para análise foi, em face do cenário no qual está inscrito os estudos da mídia e os estudos culturais do lazer, a conjuntura da visibilidade às visualidades, trazendo à tona a mediação da plataforma de mídia online Instagram e a midiatização como alicerce para as representatividades de conteúdos de lazeres dos usuários.

Nesse sentido, para que pudéssemos sistematizar uma interpretação teórica sobre a representação do lazer nas redes sociais do Instagram, tivemos em mente as definições de tempo-espaço decorrentes dos novos meios de comunicação e das tecnologias atuantes na coletividade do século XX e neste início de século XXI. Estas contribuíram para a significação e estruturação dos ambientes de convívio, sejam eles virtualizados ou não. Também potencializaram a visibilidade das práticas sociais e culturais como a de atividades de lazer e, com efeito, implicaram em mediações simbólicas para produção de sentido social. A discussão sobre o lazer aqui presente, também sugere uma reflexão sobre a nova sensibilidade que vem sendo criada com os aparelhos técnicos de registro e reprodução de imagens. Lembramos ainda que, a análise de tal pesquisa se desenvolveu conforme a investigação das especificidades dos processos simbólicos da 
comunicação midiática sobre a representação de atividades no contexto do lazer na rede Instagram. Logo, entendemos que na sociedade midiatizada existem dispositivos para estabelecer a visibilidade do que se autodeclara por lazer e que essa visibilidade autodeclarada de lazer possibilita novas formas de pensar e ampliar o conceito desta prática.

Desta forma, buscamos selecionar para este artigo aspectos teóricos da mediação do lazer no Instagram, aliado a conjuntura da visibilidade às visualidades desta prática pela apropriação da hashtag\#lazer. Por outro lado, reivindicamos a noção do conteúdo virtual do lazer de Schwartz (2003), no sentido de que a experimentação de tal rede pode gerar reflexão no campo do lazer pelo ato de uso, mas também pela mediação de conteúdos de lazeres perceptíveis que podem ampliar os sentidos de início aferidos no conjunto de atividades de lazer. Para os objetivos do presente artigo, não cabe fazer uma crítica mais aprofundada desta visão, mas apenas apresentar algumas ideias mais importantes trabalhadas na pesquisa. Sinteticamente, o artigo traz autores que compartilham os processos técnico-culturais da comunicação oferecendo possibilidades para a análise da midiatização de práticas e de conteúdos de lazer na rede.

\section{Aspectos da mediação e midiatização do lazer}

No contexto social da comunicação, indivíduos agem e reagem continuamente, em um processo de interação. Nesse processo, expressamos e buscamos o nosso lugar pessoal, a partir do qual, interagir com os outros e com a sociedade nos possibilita compreender os processos de produção de sentido nas práticas sociais. Como afirma Martín-Barbero (2008), o compacto social e perceptivo que reveste as tecnologias comunicacionais, seus modos transversais de presença na cotidianidade, suas densas formas de mediação no mundo do conhecimento e da informação estabelece os meios de sentido e alcance social. Meios em que estabelecemos conexões através da sociedade em rede e a Internet (redes) como ambiência existencial regido pela midiatização. 
Para Sodré (2009), a midiatização encontra-se vinculada às tecnologias da informação e da comunicação e permitem a multiplicação das tecnointerações. Essa interação, de acordo com Sodré (2009), é caracterizada por sua associação junto à realidade sensível, medium, acoplado a um dispositivo cultural historicamente emergente das mídias. Por sua vez, como explica o mesmo autor, o fenômeno das mídias é fruto das transformações nos modos de urbanização e no advento das tecnologias informacionais, vetorizadas pelo sistema capitalista e, o mais importante, redefinem os modos de constituição das relações humanas.

Tem sido evidência dessa midiatização, o consumo das mídias como espaço de repercussão e mediação da dinâmica cotidiana e de atividades sociais, como as no contexto do lazer, onde as relações de troca e compartilhamento de conteúdo entre perfis de usuários e a exacerbação de imagens configuram o consumo ativo como criação de sentidos e redefinição de espaços para o lazer.

Ainda referindo-se à midiatização, Sodré (2009) afirma ser este um conceito axial da mídia, que tanto abrange os meios de comunicação de massa - televisão, jornais -, quanto, segundo Martín-Barbero (2008), as novas visualidades técnico-culturais, como a Internet. É nesse aspecto que a midiatização tanto realça o processo avassalador sob a influência tecnológica, a lógica capitalista e a tecnologização desenfreada nas atividades cotidianas do ser humano, tal como ocorre no trabalho e no tempo livre e de lazer, como passa a envolver a sociedade de consumo e evidenciar o molde em que estão a ser construídas tais representações na lógica midiática: manifestam-se nas ambiências uma diversificação dos usos sociais das mídias, seja por um consumo próprio, seja por tendências instaladas - de cultura, música, entretenimento -, e demais práticas voltadas ao contexto do lazer.

Foi nesse viés que Santos e Gama (2008) definiram como o lazer tornou-se um tema crescentemente importante em diversos âmbitos da socieconomia e, mais ainda, em relação às funções da mídia. O que se desenrola nos termos dos autores é que o lazer é um tema diretamente 
relacionado com o desenvolvimento da sociedade de consumo e tornou-se uma das referências da

\begin{abstract}
mercadorização do tempo e do espaço, através de formas de interação socioeconômica lideradas tanto por processos de elitização como por processos de democratização, no acesso aos bens e serviços que lhe estão associados (SANTOS; GAMA, 2008, p. 15).
\end{abstract}

Mas não só isso, os estudos da comunicação como os da mídia e do lazer, assimilam a lógica da pós-modernidade e se reformulam dentro de uma sociedade extremamente multifacetada, em que as transformações são muitas, inserindo em outras áreas, promovem mudanças muito mais significativas no campo sociocultural e de formação de uma nova cultura. $E$, nessas condições, manifestam-se novos padrões seletivos de relações sociais em que "o desenvolvimento e a exploração destas várias tecnologias se interligaram de formas complexas com o poder econômico, político e coercitivo" (THOMPSON, 1998, p. 73).

Configurado nos processos da formação social e em suas dimensões socioculturais que competem as perspectivas de lazer nas redes do Instagram, observou-se a interação mediada que esclarece Thompson (2018). O autor recupera a reflexão das três formas de interação: interação face a face; interação mediada; quase interação mediada - formas desenvolvidas no livro "A mídia e a modernidade" e, ao mesmo tempo, adiciona um quarto tipo de interação, tendo em vista o contexto da permanente conexão em rede e a Internet (redes) como ambiência existencial regido pela midiatização. Thompson refere-se à interação mediada on-line.

Nesse tipo de interação, o autor aborda as novas formas de ação e interação que foram criadas pela comunicação mediada pelos dispositivos tecnossociais e que envolve as relações sociais reconfiguradas através do espaço e do tempo dentro das ambiências digitais. Neste aspecto, corroboramos com a ideia de Thompson em que devemos ver que "o uso dos meios de comunicação está relacionado à criação de novas formas de ação e interação, novos tipos de relações sociais e novas formas de REU, Sorocaba, SP, v. 46, n. 2, p. 323-346, dez. 2020 
relacionamento com os outros e consigo mesmo" (THOMPSON, 2018, p. 19).

Portanto, a ideia de apontarmos a relação entre mídia e lazer primeiramente pela mediação que tal conteúdo mantém com a sociedade, com o processo produtivo de trabalho e com as realizações humanas; e, em segundo, pelos vínculos que representam entre sujeitos e estes se constituem nos processos de comunicação e de sentido no que se verificou a interação on-line, pelo uso da \#lazer.

No presente estudo, esta questão destaca uma diferença entre o uso das mídias enquanto espaço de interação e o lazer como conteúdo, que se vincula aos desejos e aos vínculos de sentidos existentes e promovidos nos meios digitais e nas novas formas de ação e interação que destaca Thompson (2018). Com base nisto, nos detemos à mediação da plataforma Instagram na visibilidade das práticas cotidianas em postagens e nas visualidades marcadas pelo uso de hashtags/tags.

Entre as práticas mais utilizadas para disseminar os conteúdos no Instagram está o uso das hashtags/tags, palavra-chave (relevante) associada ou termos associados a uma informação, tópico ou discussão que se deseja indexar de forma explícita nas mídias sociais de sites e aplicativos que, quando usadas, alimenta uma interação dinâmica na rede onde é utilizada. As hashtags são compostas pela palavra-chave do assunto antecedida pelo símbolo cerquilha (\#), viram hiperlinks ${ }^{1}$ dentro da rede, indexáveis pelos mecanismos de busca. O uso de hashtags para categorizar/indexar conteúdos permite que a mídia social se alimente da conexão das redes sociais. E nessa dimensão, compreendemos a hashtag como estratégia de aglomeração temática de encontros de redes, ou seja, de interação.

Nesta reflexão, reforçamos a construção do contexto a partir de imagens e da conversação em rede no Instagram com uso de ferramentas típicas como as hashtags, além de diversos aplicativos dentro da plataforma

1 Consiste em links que vão de uma página da Web ou arquivo, uma imagem ou um endereço de e-mail ou um programa para outro, quando o usuário clica nele.

REU, Sorocaba, SP, v. 46, n. 2, p. 323-346, dez. 2020 
para serem manuseados. Artifícios que facilitam as relações de amizades, também permitem a divulgação e compartilhamento de conteúdo e determinam a apropriação/consumo dos meios de informação e comunicação. A partir dessa mediação, vislumbramos o sentido do conteúdo virtual do lazer em que, segundo Schwartz (2003), caracteriza o mundo virtual enquanto espaço de vivência de experiências de lazer.

Segundo Schwartz (2003, p. 26), "o desenvolvimento dos diversos meios de informação e comunicação, como jornal, livros, indústria da música, difusão televisiva e, especialmente, a conexão em rede, com as vias virtuais", promoveram a emergência de modalidades de transmissão cultural para atender as novas finalidades e necessidades humanas, e nesse meio, a ampliação dos interesses culturais do lazer, conforme Dumazedier (1980).

Este poder de interação pela simultaneidade virtual amplia sobremaneira a contextualidade [...], facilitam a relação têmporoespacial, modificam a forma de ação das pessoas numa dimensão própria (valores e atitudes pessoais), também numa dimensão social, em relação ao outro e em uma dimensão receptiva, ampliando a geopolítica do que seja intimidade e padrão cultural, isto é conceito e comprometimento na relação com o mundo (SCHWARTZ 2003, p. 27).

É nessa perspectiva, segundo Dumazedier (2008) que se ampliam as ofertas de atividades no contexto do lazer, de diversão, de trabalho, de criatividade que tendem a envolver grupos e a desenvolver a sociabilidade. Por outro lado, o mecanismo das hashtags, criado como incentivo à participação de usuários que se identificam com a publicação e com o assunto da postagem em rede, nos faz entender que esses "meios" deixaram de ser canais tecnológicos de transporte de uma mensagem e se tornaram o próprio conteúdo nos quais os usuários estabelecem relações uns com os outros. Logo, os meios pelo qual o lazer também é vivenciado se conjecturam nessas ambiências que caracterizamos como espaços de produção e espaços de consumo. Assim, utilizar os meios digitais como espaço e lugar de lazer torna-se uma atividade mais rotineira (do tempo livre ou não) dos indivíduos. 
Nesse aspecto, presumimos que as relações de troca e compartilhamento de conteúdo entre perfis de usuários e a exacerbação de imagens nas redes tecnológicas potencializam os processos informacionais e configuram o consumo ativo como criação de sentidos. Essa realidade informacional, de acordo com Rodrigues (2001), constitui um campo próprio e assegura a visibilidade dos demais campos sociais. Tal fenômeno se estrutura com instituições, com tecnologias, com a vida das pessoas, que se torna mais complexo pelo surgimento de formas pós-massivas de comunicação (Weblogs, Wikis, plataformas) e gera novas interações de modo não homogêneo, sendo também por elas afetadas e construídas a partir de aspectos da realidade social contemporânea. É nesse ponto que é possível compreender a midiatização que analisa Sodré (2009, p. 21), "como uma ordem de mediações socialmente realizadas no sentido da comunicação entendida como processo informacional".

Do mesmo modo, as redes digitais de abrangência global com dispositivos interconectados e processos cada vez mais digitais, transformaram radicalmente os meios de comunicação e os modos de se comunicar, aliados ao sistema financeiro capitalista, que se atêm às práticas da rede e usufrui com os seus mecanismos sociais de consumo, das transações de produtos e de serviços, do entretenimento e diversão a que o lazer se insere, para atuar concomitantemente nas transformações e nas tendências de comportamentos humanos diversos. Nesse contexto, a Internet e a comunicação digital ao tornarem-se o espaço da informação e de compartilhamento de opinião, de conteúdo, de narração de acontecimentos e principalmente de imagens, estabelece uma conjuntura da visibilidade.

A ideia dessa conjuntura, para Grossberg (2015) consiste em estar localizada em algum lugar entre a situação específica e a época, mas ocultando um espaço enorme dentro desses lugares. É nesse aspecto que o autor enfatiza a importância da cultura como uma chave para ter acesso à conjuntura e por construir a relação entre diferentes tipos de práticas numa formação social. 
Trata-se, portanto, conforme Grossberg (2015), da articulação de múltiplas dimensões sociais no que se reconhece o mundo como produto de uma construção que se expressa em uma rede de relações instáveis, variáveis e complexas. Portanto, no contexto da cultura midiática, para Hjarvard (2014), essas relações podem ser pensadas pelas apropriações sociais que se faz das tecnologias, entendidas como estruturas que condicionam e permitem a ação humana reflexiva. Mas também, no convívio em que se unem novas linguagens e novos sentidos junto as práticas dentro das ambiências digitais, repletas de tensões referentes ao objeto representado e que fazem dialogar representações e significados distintos à compreensão clássica que se tem do objeto tributário dos sentidos. Assim sendo, na interação on-line no Instagram, o fio condutor desta vinculação é a imagem que aparece como mediação da sociabilidade, da aparição do sentido e ressignificação do mesmo e do conteúdo veiculado.

É importante destacar que esse contexto da visibilidade foi favorecido por um sistema de comunicação no qual as produções midiáticas foram difundidas e repercutidas nas redes sociotécnicas e nas tecnointerações. Fato este que reflete o objeto empírico do nosso estudo e permite compreender a visibilidade mediada pelo hashtag\#lazer, relacionado a novas maneiras de agir e interagir trazidas com a mídia, conforme Thompson (2018).

\section{Aspectos da visibilidade e visualidades do lazer}

O sistema de trocas e conexões mensuradas que se consagram à tecnologização e aos meios sociais cada vez mais mediados pelas ambiências digitais e por redes sociais que produzimos e constituímos, permitiram uma reelaboração do caráter simbólico da vida social. Caráter pelo qual, destaca Thompson (2018), a informação e o conteúdo são produzidos e intercambiados no mundo social e na reestruturação dos meios pelos quais os indivíduos se relacionam entre si. Este pressuposto elabora uma nova visibilidade mediada, tornando visíveis as ações e os 
acontecimentos, como "uma arma possível no enfrentamento das lutas diárias" (THOMPSON, 2018, p. 15), aliados aos processos de interação mediada.

A criação de vários artifícios técnicos e a possível ampliação de vivências lúdicas como mecanismos propulsores das redes tecnossociais e dessa interação, segundo Sodré (2009), alteram hábitos, estilos de vida, em que os meios de comunicação criam uma nova esfera dos prazeres, da corporeidade, feito de virtualidade, de informação. Aspectos que, segundo Sodré (2010, atuam enquanto instância de produção de bens simbólicos ou culturais.

No intuito de explicar sobre a visibilidade, Martín-Barbero (2008) atribui o termo a categoria de performatividades, pois, o citado autor entende que esse conceito permite entender melhor os novos modos desse fenômeno no social "no momento em que a mediação das tecnicidades passa a ser estrutural, isto é, quando elas medeiam justamente as transformações" (MARTIN-BARBERO, 2008, p. 23).

Essa interpretação reflete a dinâmica do Instagram e as publicações dos usuários, pois, o performativo, de acordo com Derrida (1991), é uma comunicação que não descreve algo que existe fora da linguagem e antes dela, mas produz, opera ou transforma uma situação. Por outro lado, as mudanças decorrentes dos regimes de visibilidade são denominadas por Martín-Barbero (2008, p. 23) de visualidades, para perceber "as novas formas tanto da configuração do público quanto da sua percepção".

Quando um indivíduo, por exemplo, fotografa uma sala com vários amigos comendo pizza e coloca em uma rede social como o Instagram ou outro que, na mesma rede, compartilha um copo de cerveja, e estas publicações apresentam hashtags que se associam a imagem para dar sentido, essas construções demarcam a visibilidade, mas, mais particularmente, as performatividades dos usuários nas fotos quando visualizadas.

Dessa forma, entendemos as visualidades, que Martín-Barbero (2008) menciona, como as particularidades visíveis que promovem a 
transformação e o engajamento nas redes sociais para a produção de sentidos. Portanto, o efeito dessas performatividades está nas visualidades em que as novas formas tanto da configuração do público quanto da sua percepção se apresentam.

Além da abordagem de Martín-Barbero (2008), o estudo conceitual de Gomes (2013) sobre visibilidade se faz importante por este autor problematizar o papel que a trama das localizações pode ter na construção e na manifestação de um fenômeno.

Na ideia de que a visibilidade está no ângulo da percepção, Gomes (2013) busca saber como a organização do espaço participa das estratégias que oferecem ou ampliam a visibilidade. $E$, nesse aspecto, a visibilidade para o aspecto espacial que configura as relações entre imagens e posição no ciberespaço. Aqui é válido destacar o ciberespaço, tratando os aspectos práticos entre real e virtual. Pois, no sentido da representação das ações, o virtual já estaria constituído de fato, apenas esperando uma ação real para se efetivar. Essa possibilidade altera o estatuto da relação entre real e virtual, pois não é como se o real dispusesse de outras possibilidades virtuais, esse real é a atualização de um virtual que o contém. Assim, quando essa realidade virtual é mediada por meio de dispositivos ópticos ou até da interação on-line, designa "uma variedade de técnicas de modelização e visualização de dados que permitem tanto a apresentação do real pelo virtual, quanto à interpretação do real pelo virtual" (SODRÉ, 2009, p. 121).

Nos termos de Sodré (2009), o virtual figura-se no campo do "sentir", em que se pode introjetar descrições e a partir dessas, construir as próprias imagens ou ter a imagem de si mesmo e simular corporalmente as sensações do que se está realizando em decorrência da realidade desejada. Fato é que a mediação técnica potencializa as ações comuns do dia a dia na dinâmica da esfera virtual que circula e atravessa os diversos espaços sociais. "A mediação é, desta maneira, uma complexa operação semiótica que articula relações de determinação e de representação" (SODRÉ, 2006, p. 92). 
Consolidados às mídias e de forma cada vez mais generalizada e difundida no ciberespaço, a produção de imagens e o acesso às informações imagéticas passaram a ter um papel essencial nas práticas culturais e a constituir instrumentos que definem as novas maneiras de agir e interagir na sociedade. Nesse contexto, a cibercultura se apresenta promovida pela sociedade capitalista a partir de visualidades-técnicas como a Internet (MARTÍN-BARBERO, 2008), a sua trajetória de popularização como espaço de comunicação, consolidada, sobretudo, a apropriação dos novos aparatos de informação em recurso por parte de pessoas e instituições.

Em vista disso, a articulação entre redes sociais e mídias online configura uma especificidade representativa de convívio social que reflete tanto os meios quanto às culturas entre si. Com tal característica, Rodrigues (2001) compreende que as mídias constituem um campo próprio e asseguram a visibilidade dos demais campos sociais em razão da experiência fragmentada moderna. Quando reportamos aos processos comunicacionais cada vez mais moldados à estrutura conectada da sociedade em rede e a nossa cultura imbricada a midiatização, a questão levantada por Rodrigues (2001), aponta dois momentos críticos: o primeiro em que se observa a monopolização do cenário midiático para a visibilidade das demais práticas sociais; e, o segundo, pelo funcionamento regular habitual dos diferentes campos sociais em função da preservação de valores. O que ele quer dizer com isso é que o campo midiático é utilizado para tornar visível o seu próprio funcionamento, mas tendo em vista a mobilização dos outros campos sociais em torno da sua ordem de valores.

Portanto, tais dispositivos técnicos que asseguram a interação entre os usuários, independente do lugar e do momento, veicula normas e padrões hegemônicos. A visibilidade, então, retomando Thompson, possui uma natureza ambivalente para determinados campos, como a política, e de potencial construção no contexto da mediatização da esfera pública. Aqui, retomamos o estudo mais atual de Thompson (2018) sobre a interação mediada pelo advento das tecnologias digitais, em que afirma 
serem essas novas formas de interação e visibilidade os mecanismos propulsores de informação, mas que criam novos riscos, pois:

[...] a proliferação da mídia on-line significa que qualquer pessoa pode agora transmitir (ou retransmitir) imagens, mensagens e outros conteúdos simbólicos com relativa facilidade [...]. Essa democratização da transmissão transforma todos em uma fonte potencial de conteúdo visualizável e compartilhável (THOMPSON, 2018, p. 40).

Nesse sentido, a visibilidade mediada não apenas explicita fatos, mas oferece um campo de interação e de narrativas que possam vir a "comprometer ou minar a autoimagem que se deseja projetar" (THOMPSON, 2018, p. 41), principalmente no campo político. Configura, como exemplos, os vazamentos de informação e os escândalos como ameaças constantes que impulsionam os fluxos e as redes. Faz-se importante o pensamento de Thompson para compreender essa visibilidade mediada que transformam e dão alicerce a novas configurações nas atividades humanas mediadas nos espaços digitais.

Também podemos olhar a prática do lazer como um meio de espetacularização midiática, fato esse que pode ser observado em diversos locais, como no próprio espaço midiático e na política como afirma MartínBarbero (2008, p. 22):

\begin{abstract}
Se é verdade que a presença crescente das imagens no debate, nas campanhas e, ainda, na ação política espetaculariza esse mundo até confundi-lo com o do teatro, dos reinados de beleza ou das igrejas eletrônicas, também é verdade que as imagens transmitem uma construção visual do social - na qual essa visibilidade recolhe o deslocamento da luta por representação para a reivindicação de reconhecimento.
\end{abstract}

No campo das imagens, a representação se torna algo mais do que perceptível e na concepção de que a visibilidade está no ângulo da percepção, conforme Gomes (2013), essa reivindicação por reconhecimento participa das estratégias que potencializam a visibilidade de coisas, pessoas ou fenômenos. No entanto, esse movimento é interpretado pelas outras pessoas que estão a vivenciar esse meio e adquire uma significação no contexto das relações que ali se encontram e que, no princípio, é externa, 
mas também se transforma para e entre os sujeitos. Para Rodrigues (2001, p. 5), "é só no ambiente criado pela linguagem que ascendemos à consciência e que podemos considerar a visibilidade humanamente possível do mundo". De modo análogo ao modo como o uso de um ou outro instrumento determina toda a estrutura da operação de vínculos, o caráter do signo utilizado, para Smolka (2000), aparece como um momento fundamental em que o resto do processo é constituído. Por sua vez, esse lugar "reflete a configuração topológica na trama das relações de sentido em que se dá a interpretação" (SODRÉ, 2006, p. 92).

Nesse contexto, a mídia é apropriada por parte do campo político "com vista à mobilização do conjunto dos outros campos em torno da preservação do valor do poder" (RODRIGUES, 2001, p. 3). O que nos faz lembrar os elementos propulsores do lazer dos quais Rojek (2011) discute a temática do lazer em relação a poder e cultura. Essa relação envolve os processos de comunicação e interpretação que, por sua vez, estimulam e vinculam meios para interação das demandas produzidas no cenário político. O autor nos lembra da vivência apresentativa em relação às manifestações de resistência ao redor do mundo, em que traça um paralelo entre os estudos do lazer e a esfera pública. Como na perspectiva de locais que representam um espaço privilegiado para o lazer, mas que também são locais que testemunharam o nascimento de uma forma de resistência organizada e de certas redes de comunicação. Por exemplo: Coffeehouse, Pubs, bares, praças, onde pessoas tinham o seu local reservado, a sua rede social da época. $E$, somente nesses locais de lazer, distantes dos respectivos locais de trabalho, começavam a articular uma resistência. Esta desempenhada pelas redes sociais e a articulação política mediada em uma ferramenta também voltada para o lazer.

Nessa perspectiva, Rodrigues (2001) diz ser a visibilidade, inevitavelmente, o resultado do trabalho de construção dos referentes das materialidades utilizadas na atividade comunicacional. E esta ação é realizada pelos atores que se reconhecem como parceiros de interação e que estão presentes no ambiente constituído por um determinado medium, 
que para Sodré, não é o dispositivo técnico, "mas o fluxo comunicacional acoplado a um dispositivo técnico" (SODRÉ, 2009, p. 20).

Por conseguinte, a civilização de imagens permitiu que a visibilidade tornasse um valor central dos processos comunicacionais em particular da comunicação mediada. Ao analisar algumas das características dessa mediação, Thompson (2018) desenvolve uma introdução à mídia no âmbito cultural e, portanto, preocupada tanto com o caráter significativo das formas simbólicas quanto com a contextualização social dessas na interação mediada. O autor sublinha que os meios de comunicação tem uma dimensão simbólica irredutível, além de se relacionarem com a produção, armazenamento e a circulação de materiais que são significativos para os indivíduos que os produzem e os recebem dentro da visibilidade mediada. Também faz referência ao dispositivo da linguagem como parte inseparável de todo o conjunto de manifestações apropriadas que se manifestam, tanto nas palavras, como nas formas de expressão "que adotamos sequencialmente ao longo das interações sociais em que nos envolvemos" (RODRIGUES, 2001, p. 8). Ou seja, as formas tipográficas somadas às imagens e a todo o contexto de habilidades mecânicas das interfaces vão dando forma ao processo comunicacional.

Desde que o Instagram inaugurou, a empresa responsável pelas informações e divulgação das formas de uso, estabeleceu regras e dados de funcionamento para seus usuários. No seu início, como uma rede social de compartilhamento de fotos e vídeos, as principais atividades eram capturar ou carregar fotos (a partir da biblioteca de fotos do celular), fazer edição das imagens e postar nas redes. Atualmente para personalizar o conteúdo e permitir mais criatividade para as publicações, para estimular os usuários e que possam usufruir de uma forma mais bem-aproveitada, diversos aplicativos que complementam o Instagram foram instalados, a partir da escolha do perfil ou da empresa, para edição de fotos, edição de vídeos ou montagens, criação de vídeos com trilhas sonoras, estatísticas, pesquisa de hashtags e até aplicativo que programa as publicações dos usuários. Este tipo de aplicativo é utilizado por empresas e profissionais de 
social media, pois permitem otimizar as tarefas do trabalho. São recursos disponíveis com o objetivo de captar várias curtidas e melhorar a qualidade das fotos dos perfis da rede, dentre outros aspectos, possibilitar a interação e a criação e visualidades de produtos.

Dessa maneira, articulamos essa visibilidade a uma expressão visual da percepção social e culturalmente construída pelas relações interligadas nesses meios digitais, por sua vez, potencializada nos sites de redes sociais e ressignificada através das visualidades delimitadas por ferramentas do próprio meio. Essa abordagem, portanto, reflete o processo de produção de sentidos que, de acordo com Orlandi (2005), se compõe em uma materialidade que Ihe é própria. Para tanto, o significado não se estabelece na indiferença dos materiais que a constituem, ao contrário, é na prática material significante que os sentidos se atualizam, ganham corpo, significando individualmente.

Contudo, em um contexto de grande produção e compartilhamento de imagens online, que se desdobrem sobre as mudanças na significação, esses dados permitem avaliar se há reutilização e apropriação, bem como contribuem para a compreensão de aplicabilidades possíveis com a junção entre indexação semântica e elementos visuais, ou seja, aquelas que resultam da relação entre a imagem e o texto. Este aspecto traz à tona o questionamento de Gomes (2013) que se dirige propriamente às "condições de visibilidade segundo um ângulo da percepção, ou seja, a natureza da questão é sobre aquilo que é espontaneamente observado pelo olhar" ( $p$. 10) e no presente, na mediação da plataforma de mídia online Instagram e a interação mediada pela hashtag. Nesse viés, entendemos as visualidades, como as particularidades visíveis performatizadas que se estabelecem no uso da hashtag \#lazer em imagens e permitem pensar a relação da transformação dos meios e dos sujeitos e que promove também, o engajamento nas redes sociais para a construção de sentido. Esse pressuposto recupera as reflexões de Thompson, no contexto da complexa dinâmica de poder relacionados ao conteúdo simbólico que é transmitido e ressignificado na rede Instagram. 


\section{Aspectos da mediação e apropriação da hashtag \#lazer no Instagram}

Diante do cenário da interação mediada, a rede Instagram, como uma plataforma de mídia online, mostra claramente o campo de expressão visual sobre leituras de mundo diversas em que o uso de imagens e do imaginário generaliza-se. Quer as produzimos quer as olhemos, somos levados à interpretação das publicações que são representações codificadas da realidade que transitam entre si e o outro para explorar o modo como somos intrínseca e culturalmente. Na perspectiva de que toda a sociedade é formada por inúmeras construções de sentidos vinculados a processos sociais, sendo o mais importante a interação, é importante observar que a rede social dialoga com o imaginário das pessoas, não só pelo universo de imagens, mas na relação de causa e efeito existente entre o ambiente da rede e os usuários que interagem entre si.

Esta reflexão remonta a nossa relação com o universo tecnológico e a necessidade de exposição desencadeada pelas visualidades condicionadas dos meios, sentir-se alguém no mundo como expressão e como representação. Esse campo processa-se nessa formação de vínculos sobre as estratégias sensíveis, no que Sodré (2009) refere-se aos jogos de vinculação dos atos discursivos às relações de localização e afetação dos sujeitos no interior da linguagem. E, ainda, "a vinculação é propriamente simbólica, no sentido de uma exigência radical da partilha da existência com o Outro, para além de qualquer racionalismo instrumental ou de qualquer funcionalidade societária" (SODRÉ, 2006, p. 93). E, nessa perspectiva, estamos sempre criando um novo paradigma em que as agências, os modos de falar e de discursos narrativos refletem o interesse e a vinculação de desejos, "onde o sentido troca a lógica circulação de valores do enunciado pela co-presença somática e sensorial dos actantes" (SODRÉ, 2006, p. 10). Essas suspeitas são embasadas como uma configuração perceptiva e afetiva que recobre uma nova forma de conhecimento e nessa questão, de cultura. 
Essa ação mostra também as habilidades tecnossociais construídas e necessárias para construir laços de amizade e de afeto que são importantes para criar vínculos. Contudo, para Sodré (2006), vincular-se, diferentemente de apenas relacionar-se, é muito mais do que um mero processo interativo. Isto "porque pressupõe a inserção social e existencial do indivíduo desde a dimensão imaginária (imagens latentes e manifestas) até as deliberações frente às orientações práticas de conduta, isto é, aos valores". (SODRÉ, 2006, p. 93).

Desde a sua fundação, em 2010, a plataforma de mídia social aposta em inovações aliadas ao teor imagético que se instaura na realidade da produção midiática e na conexão dos sentidos. E aqui, ressalta-se a interatividade promovida pela plataforma, os recursos disponíveis no aplicativo e a habilidade para conectar "amigos no Insta", no qual $87 \%$ são usuários ativos na faixa etária de 12 a 34 anos. O potencial de habilidade da mídia foi uma medida tomada em 2012, quando o Instagram foi comprado por Mark Zuckerberg, dono da rede social Facebook. O aplicativo foi inaugurado para o público, em outubro de 2010, desenvolvido pelos engenheiros de programação Kevin Systrom e Mike Krieger. Após a propriedade do Facebook, algumas mudanças para simplificar e tornar mais prático e funcional o processo de registro de novas contas e novas ferramentas como a criação do Instagram Stories ou Histórias do Instagram, que dá a possibilidade dos usuários criarem vídeos do seu dia a dia e que desaparecem depois de 24 horas da sua publicação. Ou a mais recente inovação da plataforma que permite ao usuário exercer influência sobre o conteúdo ou a forma da comunicação mediada no modo offline. 0 que era uma ambiência para postagem de fotos, apresenta novos recursos e ferramentas que ajudam a promover mais o acesso e aumentar as visualizações das redes e do conteúdo destes.

Outra construção alude à visualização de imagens que propicia uma dinâmica nos feeds da rede ao mobilizar milhões de usuários com base em hashtags indicadas pela plataforma. A proposta é a de que cada vez mais momentos incríveis sejam compartilhados nas redes e a publicação mais 
visualizada potencializa os usuários de perfis ao postarem toda semana algumas das fotos dos usuários e explicações na postagem sobre o momento retratado.

De fato, uma das formas de aumentar o engajamento nas fotos do Instagram é usar hashtags, por ser esta uma forma de evidenciar a representatividade daquele grupo que compreende a mídia como um espaço de interesse comum. As mais populares da rede social são utilizadas para possibilitar os fluxos de conteúdo. Como tags com o termo "instagram" e "insta...", por exemplo: \#instagram \#instagramer \#instaplant \#instaboy \#instalike \#instagay \#instagood e \#instadesign, nas legendas em menção as ações representadas nas imagens. Essas terminologias consolidam a outro aplicativo criado para o Instagram, o Instagramers. Este aplicativo contém um manual com dicas de como utilizar melhor o Instagram e facilitar a busca por assuntos que realmente interessam os usuários adeptos da rede. Há tutoriais que ensinam a organizar reuniões com outros fãs do aplicativo, interesse em aumentar a popularidade e encontrar um estilo próprio que engaje o perfil do usuário. A sua interface possui ainda notícias, releases, entrevistas com os usuários mais participativos, além de uma lista com mais de trezentos fã-clubes espalhados pelo mundo. Por exemplo, os milhões de usuários que cooperam utilizando a hashtag \#tbt. O termo \#tbt significa \#throwbackthursday, que pode ser traduzido do inglês para "quinta-feira do retorno" ou "regresso".

Como observado nas publicações com as hashtags \#lazer e \#tbt, esta é a hashtag usada, teoricamente, às quintas-feiras. O uso se tornou uma brincadeira que nos remete as lembranças de registros antigos. O usuário publica alguma foto do passado e que vincula a uma lembrança feliz ou saudosa, um momento vivenciado e por este discursado. Isso porque para postar com a hashtag \#TBT é preciso seguir umas regras, mas que poucos usuários se atem. Dentre essas regras, a de que a foto tenha no mínimo cinco anos e o post seja feito a cada duas semanas. Regras que se perdem pela dinamicidade das redes sociais e as particularidades dos perfis. Neste ponto, alegamos o caráter de lazer mediado no que confere em artifícios 
das mídias para produção de conteúdo e a interação que por si, possibilita um contentamento lúdico. O que se observa nas publicações são imagens, em sua maioria, que remetem a momentos de lazer representados nas viagens, passeios, realização de atividades físicas ou vivências do cotidiano com expressões e menções divertidas. Obviamente, outras tantas representações são evidenciadas que assimilam as subjetivações e objetivações dos perfis. Além do conjunto de tags que também possibilitam outros sentidos sociais. Esta interação pode ser vista nas publicações em que a hashtag \#tbt está associada à imagem da hashtag \#lazer (Figura 1).

Figura 1- Hashtags \#tbt e \#lazer nas publicações dos usuários

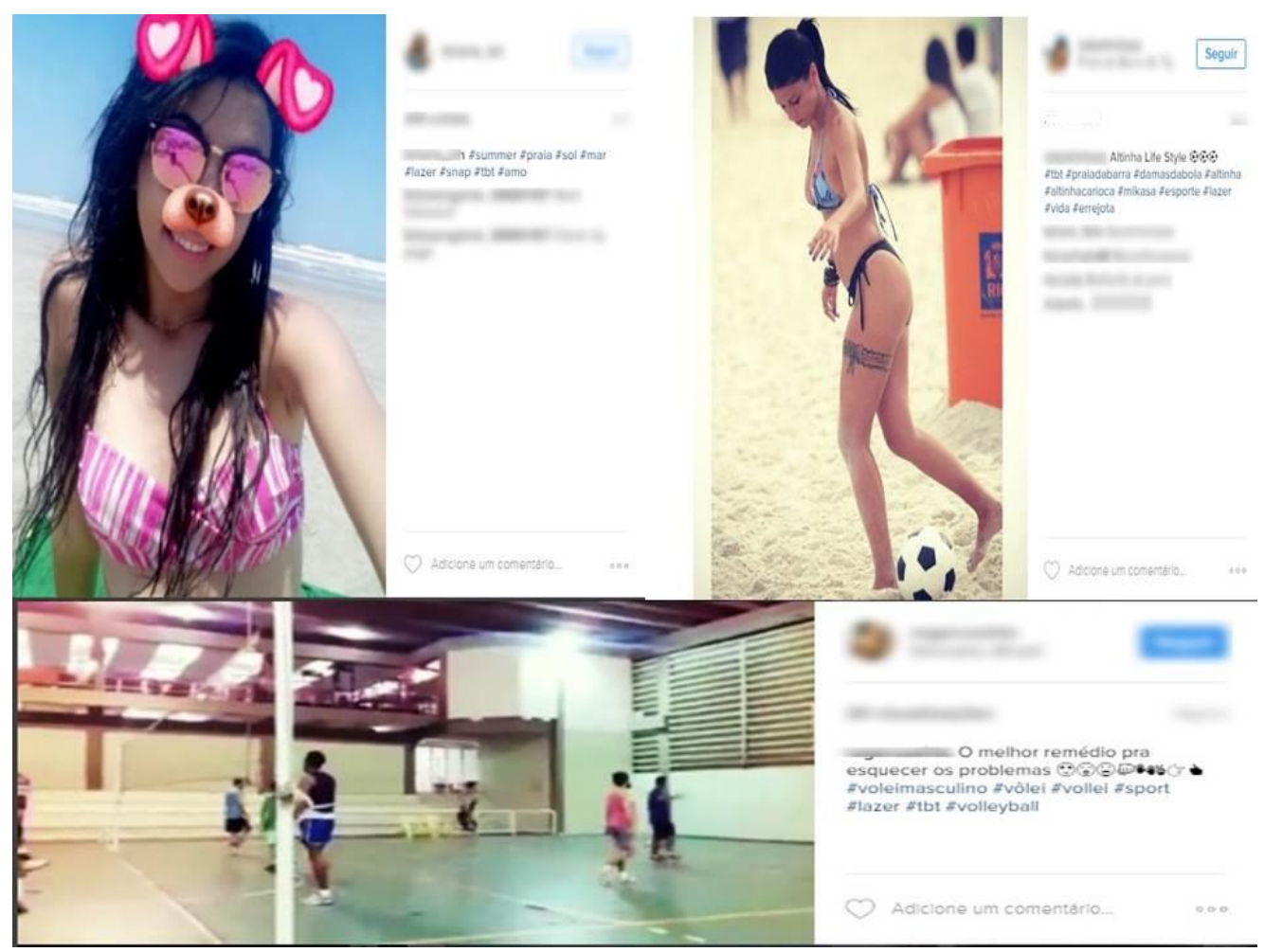

Fonte: INSTAGRAM. Disponível em: https://www.instagram.com/?hl=pt-br. Acesso em: 31 jan. 2017. 
Neste propósito, partilhamos com o pensamento de Rechi e Ladewig (2014), pois mesmo que a autora aborde as influências das transformações em relação ao tempo e espaço de lazer no espaço urbano para a fruição da cultura lúdica, essa dinâmica pode ser diagnosticada no espaço virtual que acarreta numa visibilidade simbolizada por uma ferramenta da hashtag e configuram os três pilares estudados pela autora: espaço, tempo e ludicidade. A partir da ideia de que é fundamental usar a hashtag para colocar as fotos dos usuários entre outras fotos como dessa brincadeira do \#TBT e isto consolida, segundo Schwartz (2003), uma atividade em que os participantes possuem uma maneira formal de proceder e estão sujeitos a regras se direcionados e conduzidos nas redes. Nesse aspecto, a virtualidade descentra o tempo e espaço, mas é potência para a ludicidade. Logo, associa-se ao conteúdo virtual do lazer por presumir uma atividade lúdica livre, consciente supostamente fora da vida rotineira, que absorve a pessoa intensamente e se processa dentro de seus próprios limites de tempo e espaço e como já exposto, de acordo com regras fixas a critério do usuário e de um modo ordenado na ambiência digital da plataforma.

Fato é que a circulação de conteúdos por meio de diferentes sistemas de mídia, na plataforma, depende fortemente da participação ativa dos usuários. Logo, a criação de ferramentas é atualizada para interação dos usuários e "para criar ondas de intensa participação em experiência de tempo e de espaço, a partilha do sensível, a intensidade da comoção e engajamento construídos num complexo sistema de espelhamento" (MALINI; ANTOUN, 2013, p. 14).

Por conseguinte, o entrelaçamento com a esfera de publicação dos perfis do Instagram e suas redes demonstra a construção de narrativas e situações particulares em tempo real dos usuários, muitas vezes baseada na hashtag de interesse em que articulam acontecimentos públicos e privados do cotidiano. Essa utilização do ciberespaço constitui-se, assim, segundo Sodré (2009), como uma realidade simulada, mas realística, verossímil. Já para Gomes (2013), essa produção se concretiza apenas com a apropriação e interpretação das diferentes mensagens pelos usuários em 
que se verifica as mídias sociais, enquanto um conjunto diverso de aplicações para internet construídas com base nos fundamentos de criação e troca de conteúdo gerado pelos usuários, em ambientes digitais, em que assumem uma importância significativa na disseminação de produção de sentido nas práticas sociais.

\section{Considerações finais}

Com base em autores que compartilham os processos técnicoculturais da comunicação e oferecem possibilidades para a análise da midiatização de práticas e de conteúdos de lazer na rede Instagram, percebemos que o lazer também reflete os valores e as dinâmicas da interação mediada nas redes e a convocação por hashtags.

Neste aspecto, consideramos a visibilidade atrelada às visualidades do lazer em imagens compartilhadas por usuários/perfis públicos do Instagram com a hashtag\#lazer. O que nos permitiu observar o campo de visibilidade, sociabilidade, temporalidades, pluralidades e expressões diversas respaldadas pelo consumo visual e reprodução de imagens que a rede suscita. Ademais, é este o processo que talvez nos leva a utilizar os recursos da linguagem de maneira apropriada em cada um dos ambientes em que reconhecemos mútua e reciprocamente a presença de outros humanos que, como indivíduos, estabelecem trocas e experiências para visibilidade possível. $\mathrm{E}$, neste sentido, o termo visibilidade está diretamente relacionado a tecnologização, onde o lazer se configura como conteúdo do meio que destaca os acontecimentos e as particularidades visíveis na interação mediada e no poder da comunicação por imagens.

Nossa intenção, com esta discussão, foi mostrar, dentro do critério sobre a produção de sentido nas práticas sociais de lazer, que a experimentação de uma rede como o Instagram pode ser vista sob dois aspectos: o lazer é o ato do uso ou o lazer é conteúdo que pode se ampliar a partir desse uso. Logo, tais conjecturas repercutem na ludicidade como um aspecto da cultura vivenciada na ambiência da rede Instagram através 
da interação mediada. Além disso, possa ser uma saída para a complexa relação que existe dentro de um sistema de (re)apropriação, de interpretação das atividades humanas e ressignificação das identidades individuais e coletivas que ali interagem e como espaço de trocas que alimentam o processo criativo.

Desse modo, a mediação, apropriação e visibilidade das práticas sociais como a de atividades de lazer no Instagram, constituem e possibilitam mecanismos de entendimento para ressignificação e ampliação do que se compreende por lazer. Perspectivas que confirmam a ideia do lazer midiatizado na rede em meio as diversas expressões de grupos sociais e indivíduos que consomem, se informam, manifestam e (re)produzem conteúdos, por meio de imagens e das visualidades do lazer na interação mediada pela hashtag\#lazer.

\section{Referências}

DUMAZEDIER, Joffre. Sociologia empírica do lazer. São Paulo: Perspectiva, 2008.

GOMES, Paulo. O lugar do olhar: elementos para uma geografia da visibilidade. Rio de Janeiro: Bertrand Brasil, 2013.

GROSSBERG, Lawrence. Lutando com anjos: os estudos culturais em tempos sombrios. Matrizes, São Paulo, v. 9, n. 2, 2015, p. 13-46.

HJARVARD, Stig. Midiatização: conceituando a mudança social e cultural. Matrizes, São Paulo, v. 8, n. 1, p. 21-44, 2014.

LIMEIRA, Vivianne. Mediações de lazer no Instagram: imagens, visualidades e sentidos. 2018. 99 f. Dissertação (Mestrado em Estudos da Mídia) - Centro de Ciências Humanas, Letras e Artes, Universidade Federal do Rio Grande do Norte, Natal, 2018.

MALINI, Fábio; ANTOUN, Henrique. A internet e rua: ciberativismo e mobilização nas redes sociais. Porto Alegre: Sulina, 2013.

MARTÍN-BARBERO, Jesús. Novas visibilidades políticas da cidade e visualidades narrativas da violência. In: COUTINHO, Eduardo [Org.]. Comunicação e contra-hegemonia: processos culturais e comunicacionais de contestação, pressão e resistência. Rio de Janeiro: Editora UFRJ, 2008.

RECHIA, Simone; LADEWIG, Ivo. Espaços de lazer, meio ambiente e infância.

Revista Brasileira de Estudos do Lazer, Belo Horizonte, v. 1, n. 3, p. 67-83, 2014. Dossiê Lazer e Meio Ambiente

RODRIGUES, Adriano. Estratégias da comunicação. Lisboa: Presença, 2001. 
ROJEK, Chris. O lado obscuro do lazer: formas anormais. In: FORTINI, J. L. M. et al. [Org.]. Desafios e perspectivas da educação para o lazer. Belo Horizonte: SESC/Otium, 2011. p. 137-148.

SANTOS, Norberto; GAMA, António. Lazer: da libertação do tempo à conquista das práticas. Coimbra: Imprensa da Universidade de Coimbra, 2008.

SCHWARTZ, Gisele. O conteúdo Virtual do lazer: contemporizando Dumazedier. Licere: Revista do Programa de Pós-graduação Interdisciplinar em Estudos do Lazer, Belo Horizonte, v. 6, n. 2, p. 23-31, 2003.

SMOLKA, Ana Luiza B. O (im)próprio e o (im)pertinente na apropriação das práticas sociais. Cadernos CEDES, Campinas, v. 20, n. 50, p. 26-40, 2000. SODRÉ, Muniz. Antropológica do espelho: uma teoria da comunicação linear e em rede. Petrópolis: Vozes, 2009.

SODRÉ, Muniz. As estratégias sensíveis: afeto, mídia e política. Petrópolis: Vozes, 2006.

THOMPSON, John. A mídia e a modernidade: uma teoria social da mídia. Petrópolis: Vozes, 1998.

THOMPSON, John. A interação mediada na era digital. Matrizes, São Paulo, v. 12, n. 3, p. 17-44, 2018. 